\title{
0 \\ EDITORIAL \\ LA PAZ EN COLOMBIA: UNA OPORTUNIDAD PARA LA CONSTRUCCIÓN DE UN PAÍS MÁS JUSTO
}

DOI: http://dx.doi.org/10.18597/rcog.765

a firma de la paz entre el Gobierno de Colom-

bia y las Fuerzas Armadas Revolucionarias de Colombia (FARC), el 26 de septiembre, y su refrendación por el pueblo el día 2 de octubre de 2016, constituyen el punto de partida para que Colombia evolucione, desde las viejas estructuras que tienen raíces en la Colonia y los primeros estadios de la nación, a las estructuras de los países con mayor desarrollo social en el siglo XXI, basadas en la igualdad y la equidad, el respeto por el medio ambiente y por las diferencias, $\mathrm{y}$ la lucha contra la corrupción.

La propiedad de la tierra ha sido el origen de las constantes guerras que hemos vivido desde nuestra fundación como nación hasta la segunda década del siglo XXI. Este esquema de propiedad de la tierra surge en la Conquista, cuando los españoles se convierten en dueños de la tierra, y continúa en la Colonia y los inicios de la República, cuando los descendientes de los españoles, los criollos, la heredan. En estas tierras trabajaban los indígenas, sus propietarios originales, o sus descendientes, los campesinos, bien porque eran obligados o para lograr su sustento; ellos quedaron excluidos de la propiedad de la tierra (1). Bajo este esquema los "señores" eran dueños del campo, de su producción y hasta de parte del tiempo de los trabajadores. Este ha sido un esquema de propiedad con rasgos de sistema feudal (2).

Este modelo propició el desarrollo de varias guerras en el país, entre quienes querían mantener el statu quo y quienes querían cambiar ese estado de cosas. De esta manera se presentan: la guerra de la mitad del siglo XIX, y la de los Mil Días a finales del siglo XIX, que determina la pérdida de Panamá en 1903. La época de violencia liberal-conservadora a finales de los años cuarenta e inicios de los cincuenta, periodo en el cual es asesinado Jorge Eliécer Gaitán. de Jorge Eliecer Gaitán. En esta época se presentan los primeros brotes del paramilitarismo en Colombia (3). Este periodo finaliza con la dictadura de Rojas Pinilla y la posterior creación del Frente Nacional. Este acuerdo se caracteriza por la distribución del poder y sus réditos entre liberales y conservadores por periodos iguales durante 16 años, excluyendo cualquier otra alternativa política, lo que determina finalmente el surgimiento de las guerrillas liberales que se transformaron en comunistas en los años sesenta (4). En este periodo la corrupción, presente desde la constitución de la República, echa raíces definitivas en la política colombiana. En este periodo se caracteriza, además, por el clientelismo, la exclusión social y la represión (5).

Con la aparición del narcotráfico a mediados de los años setenta surge un nuevo grupo de poder en Colombia, el de los traficantes de droga, se deteriora las estructuras éticas de la sociedad colombiana; la plata fácil es el nuevo paradigma, los recursos de esta actividad entran a fortalecer a la guerrilla y a los grupos paramilitares - provenientes de la alianza de ciertos sectores de la sociedad civil, los cuerpos de seguridad del Estado y el narcotráfico-, que surgen posteriormente como respuesta a los grupos guerrilleros (6). Como resultado hay mayor pobreza, se incrementa la corrupción, se produce un nuevo proceso de concentración de la tierra, hay exclusión social y represión selectiva (7).

En este escenario iniciamos el siglo XXI; sin embargo, el efecto de ciertas dinámicas, como el rechazo generalizado de la población a las acciones guerrilleras 
relacionadas con el secuestro, la extorsión y el asesinato, y el cambio en la dinámica de la guerra -en la cual el Estado logra importantes victorias militares que minan el pie de fuerza y logra eliminar varios miembros de sus cuadros de mando-, y la posibilidad de lograr cambios estructurales en la nación colombiana, llevan a que las FARC entren en un proceso de negociación (8) que terminará en la firma del acuerdo de paz y su validación por la sociedad colombiana. Sin embargo, este no es el fin de los problemas que llevaron a la guerra, sino el inicio de los cambios que se requieren para la transformación de Colombia como país capaz de responder a los desafíos que presenta el siglo XXI.

La sociedad colombiana actual debe ser capaz de responder a fenómenos tales como: la globalización dada por las tecnologías de la información y las comunicaciones, el reconocimiento de los derechos de las minorías y del respeto por las diferencias, el uso indiscriminado de los recursos no renovables que ha conducido al calentamiento global y amenaza nuestros ecosistemas y, por último, la lucha contra la corrupción como fuente de pobreza e inequidades. La paz constituye un escenario propicio para estos cambios.

La firma del acuerdo de paz y su aprobación son solo el primer paso de la transformación que debe seguir la sociedad colombiana para el logro de una paz estable y duradera, basada en la tolerancia y el respeto por quienes tienen un pensamiento diferente, por la sanción social a quienes toman dineros públicos para su beneficio particular o a quienes desde el sector privado buscan, mediante maniobras no éticas, incrementar sus ingresos a costa de aquellos que compran los bienes o requieren los servicios que producen. Transformación que incluye el respeto y la protección por nuestros recursos naturales más preciados como son los páramos y las selvas, las fuentes de agua y el oxígeno, que junto a nuestros ríos y mares representan el hábitat de numerosas especies animales y son fuente de seguridad alimentaria de nuestras comunidades. Se requiere lograr que la riqueza del país llegue también a los indígenas, a los campesinos y a la clase obrera, para que se logre un país más equitativo.
Para el sector salud el desafío es mayor, en especial en la salud de la mujer durante la niñez, la adolescencia, la gestación y la menopausia. En el área de la ginecología y la obstetricia debemos trabajar para que se solucionen, con el concurso de otros sectores, los aspectos económicos, sociales y culturales que determinan que la mortalidad materna e infantil se concentre principalmente en las regiones más pobres $(9,10)$ y en las minorías (11), para que las mujeres conozcan sus derechos sexuales y reproductivos, para que los afiliados al régimen subsidiado por el Estado tengan los mismos resultados en salud que los del régimen contributivo (12), para que los problemas de calidad en la atención sean mínimos tanto en las instituciones públicas como en las privadas (13), y para que los actores del sector cumplan con sus responsabilidades en el marco de la Ley Estatutaria de Salud.

La Federación Colombiana de Obstetricia y Ginecología (FECOLSOG) se sumará a los esfuerzos para que la paz se consolide en Colombia, en un esfuerzo nacional por tener un mejor país para nuestros hijos.

\section{Hernando Gaitán-Duarte, MD MSc Editor}

\section{REFERENCIAS}

1. Bushnell D. Colombia una nación a pesar de sí misma. Bogotá: Planeta; 1996.

3. García-Peña D. El paramilitarismo. El Espectador, Bogotá, marzo 22 de 2007. p. 54-5.

4. El Comercio. El origen de las FARC, la guerrilla más antigua de América Latina [visitado 2016 Sep 15]. Disponible en: http://elcomercio.pe/mundo/ actualidad/origen-farc-guerrilla-mas-antigua-americalatina-noticia-1464153

5. Banco de la República. Biblioteca Luis Ángel Arango. Frente Nacional. Acuerdo bipartidista y alternación en el poder [visitado 2016 Sep 15]. Disponible en: http:// www.banrepcultural.org/node/32857

6. Velásquez Rivera E. Historia del paramilitarismo en Colombia. História São Paulo. 2007;26:134-53.

7. Camacho Guizado A. Narcotráfico y sociedad en Colombia: contribución a un estudio sobre el estado 
del arte. Boletín Socioeconómico. 1992 [visitado 2016 Sep 15]; 24 y 25. Disponible en: http://cms. univalle.edu.co/socioeconomia/media/ckfinder/ files/Narcotrafico\%20y\%20sociedad\%20en\%20 Colombia\%20Contribucion\%20a\%20un\%20 estudio\%20sobre\%20el\%20estado\%20del\%20arte.pdf

8. Ríos Sierra J. Del Caguán a La Habana. Los diálogos de paz con las FARC en Colombia: una cuestión de correlación de fuerzas. Revista de estudios en seguridad internacional. Granada (España). [visitado 2016 Sep 15]. Disponible en: http:// http://www. seguridadinternacional.es/revista/?q= content/delcagu\%C3\%A1n-la-habana-los-di\%C3\%A1 logos-depaz-con-las-farc-en-colombia-una-cuesti\%C3\%B3n-de

9. Sandoval-Vargas YG, Eslava-Schmalbach JH. Inequidades en mortalidad materna por departamentos en Colombia para los años 2000-2001, 2005-2006 y 2008-2009. Rev Salud Pública. 2013;15:529-41

10. Díaz Y. ¿Es necesario sacrificar la equidad para alcanzar el desarrollo? El caso de las inequidades en Mortalidad infantil en Colombia. Facultad de Economía, Publica- ciones Universidad de los Andes [visitado 2016 Sep 20]. Disponible en: https://economia.uniandes.edu. co/component/booklibrar y/478/view/46/Documentos\%20CEDE/510/es-necesario-sacrificarla-equidadpara-alcanzar-desarrollo-el-caso-de-lasinequidades-enmortalidad-infantil-en-colombia

11. El Espectador. La desnutrición está exterminando a los niños en La Guajira, febrero 3 de 2016 [visitado 2016 Sep 22]. Disponible en: http://www.elespectador.com/ noticias/nacional/desnutricion-esta-exterminando-losninos-guajira-articulo-614468

12. Pérez-Olivo J, Cuevas EL, García-Forero S, CampoArias A. Maternal near miss morbidity in Colombia: variables related to opportune access to health care related to the number of inclusion criteria. Rev Fac Med. 2014;62:553-8.

13. García F. Los determinantes de la calidad de la atención en salud: el caso del control prenatal. Coyuntura económica: investigación económica y social. 2009:39:6-67. 